\title{
Influences of Purline Stiffness on the Stability Performance of Portal Frame
}

\author{
Du Gang ${ }^{1,}$, , Liu Feng ${ }^{1, b}$ and Xu Lehuan ${ }^{1, c}$ \\ ${ }^{1}$ School of Civil Engineering, Shandong Jianzhu University,Jinan City, Shandong Prov. China \\ 250101 \\ a13808938311@126.com, ${ }^{\mathrm{b}}$ Ifeng@sdjzu.edu.cn, ${ }^{\mathrm{c}}$ wzx11110929@126.com
}

\section{Keywords: Portal Frame, Purline, Stiffness, Stability}

Abstract. In order to study the influence of purline stiffness in portal frame on the stability performance of portal frame, this paper establishes the finite element model of portal frame-purline-knee bracing system and conducts buckling analysis and ultimate bearing analysis of the system by use of ANSYS finite element software, discussing the influence of different purline stiffnesses on the stability performance of portal frame under different spans respectively. The analysis results indicate that for the portal frames with small spans, there are no obvious effects in improving the stable bearing capacity of portal frames via the increase of purline stiffness; for the portal frames with large spans, the increase of purline stiffness can greatly improve the stable bearing capacity of portal frame.

\section{Introduction}

In December, 2005, a plant in Weihai collapsed in snowstorm weather [1,2], and almost all purlines had lateral bucking failures. After investigation, the reason was that the design section of purlines was relatively small, and purlines had buckling torsion under accidental load effect, causing the steel beam flange to lose support. Under the "pulling" action of external load and purline, steel beams were bent and twisted, pulling steel columns and causing steel columns to topple and fall inwards, and the drawing force generated damaged the anchor bolts, causing the progressive collapse of the whole rigid frame.

Purlines in portal frame structures play an out-of-plane supporting role in rigid frame, and the stability of rigid-frame beam is mainly guaranteed by purlines and knee bracings. As primary members, purlines play important roles in the stability of the whole construction. Purlines are generally made of thin-walled cold-formed steel, and they are easy to have buckling failure. Therefore, it is of certain significance to carry out the research of influences of purline stiffness on the stability performance of portal frame. This paper carries out buckling analysis and ultimate bearing analysis of portal frame-purline-knee bracing system by use of the finite element program ANSYS and discusses the influence of purline stiffness on the stability performance of portal frame.

\section{Finite element model}

\section{Description of basic structure}

The basic structural layout selected in the paper is shown in Figure 1. The column space of portal frame plant is $6 \mathrm{~m}$, and the elevation of column cap is $10 \mathrm{~m}$; the total length is $42 \mathrm{~m}$; the roof slope is 1:10; the column feet are hinged; the lateral brace space of roof is $6 \mathrm{~m}$; the beam columns are made of $\mathrm{H}$-shaped steel; the rolled steel is Q235; simply-supported purlines are made of thin-walled cold-formed steel $\mathrm{C} 180 \times 80 \times 3$, with the space of $1.5 \mathrm{~m}$; the dip angle of knee bracing is 450 ; the equal angle steel

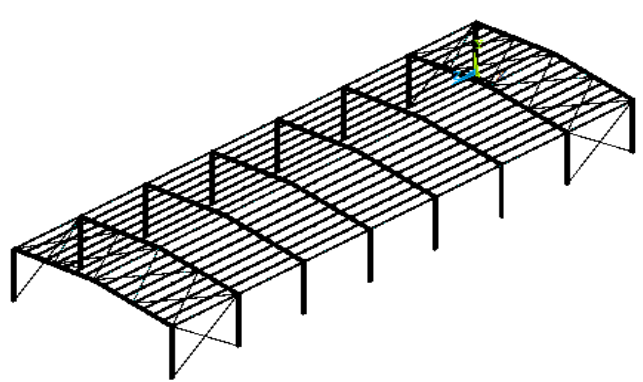

Fig. 1 Structural Layout Plan of Portal Frame Plant L50x3 is adopted. 
There have already had researches indicating that $[3,5]$ the depth-span ratio of portal frame has a large influence on its buckling failure and ultimate bearing capacity. This paper takes the portal frame with medium and large spans as research object and builds the basic structure analysis model of five different spans. The calculation of basic structure meets the requirement of specification [6,7] and regulation [8]; the sectional dimension of beam column is shown in Figure 1.

\section{Building of finite element model}

This paper selects a truss of rigid frames and associated supports, purlines and knee bracings to build a rigid frame-purline-knee bracing system for stability analysis and calculation. The lateral support in simplified model is simplified as a lateral fixed point; purline takes a half of the length, and it is hinged with the top flange of cant beam; the other end adopts directional support, and the calculation diagram is shown in Figure 2; the connection of knee bracing and the lower flange of cant beam and purline are hinged; the column feet are hinged. The roof load of portal frame is simplified as the concentrated load of the position of connection between purline and cant beam. The finite element model is shown in Figure 3.

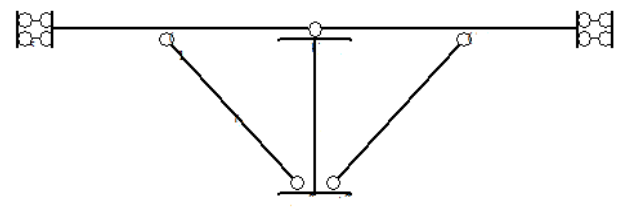

Fig. 2 Calculation Diagram of Portal Frame

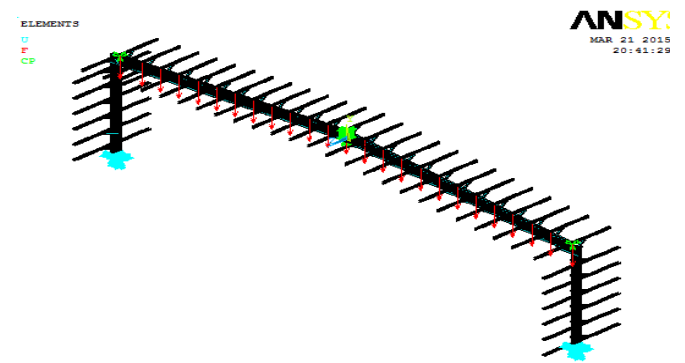

Fig. 3 Finite Element Model

\section{Selection of unit}

The beam column adopts Shell Element Shell63, and the influence of such factors as residual stress, initial geometric imperfections, second-order effect and plastic distribution are taken into account; purlines have bending deflection and shear deformation and they adopt Beam188 unit; knee bracings are axial tension and compression components, and they adopt link 8 unit.

\section{Selection of parameters}

This paper mainly studies the influence of purline stiffness on the stability performance of portal frame, so the sectional stiffness (second moment of area) of basic structure analysis model is 1.0; change the section to make its stiffness take such values as 0.6, 0.8, 1.2 and 1.4.

\section{Buckling analysis of spatial stability}

The eigenvalue buckling analysis can determine the critical load when the structure begins becoming unstable and the corresponding buckling mode and predict the theoretical critical load of ideal linear elastic structure, providing nonlinear analysis to some extent.

In consideration of the influence of five different purline stiffnesses, the buckling analysis of portal frames with five different spans is conducted to obtain the buckling mode graph and buckling factor. In the analysis model, there are four types of buckling modes: 1. Out-of-plane overall buckling of rigid frame; 2. Buckling of cant beam; 3. Buckling of cant beam and purline; 4. Buckling of purline.

The buckling mode analysis indicates that the buckling modes of the first order of every calculation model are the out-of-plane overall buckling of rigid frame; as for the portal frame with the spans of $24 \mathrm{~m}$ and $30 \mathrm{~m}$, under the condition of different purline stiffnesses, the buckling modes of the first three 
orders have no obvious change, which means that purline stiffness under the condition of such two spans almost has no influences on the buckling mode of portal frame; as for the portal frame with the span of $36 \mathrm{~m}$ in the model wherein the purline stiffness is 0.6 and the portal frame with the span of $42 \mathrm{~m}$ in the model wherein the purline stiffness is 0.6 and 0.8 , the buckling mode of the second order has buckling of purline, while the buckling modes of the second order in other purline stiffness models are buckling of cant beam and purline, so the buckling modes are different; as for the portal frame with the span of $48 \mathrm{~m}$ in the model wherein the purline stiffnesses are $0.6,0.8,1.0$ and 1.2, the buckling mode of the second order has buckling of purline and cant beam, while the buckling mode of the second order in the model wherein the purline stiffness is 1.4 has buckling of cant beam, no buckling of purline. The changes of latter three spans indicate that purline stiffness has large influences on the buckling mode of large-span portal frames.

The eigenvalue factors of every model buckling analysis are shown in Table 2. With the eigenvalue factor of buckling mode of the first order in the model wherein the purline stiffness of different span is 0.6 , a broken line graph is drawn according to the eigenvalue factors of every span model with different purline stiffnesses, as shown in Figure 4.

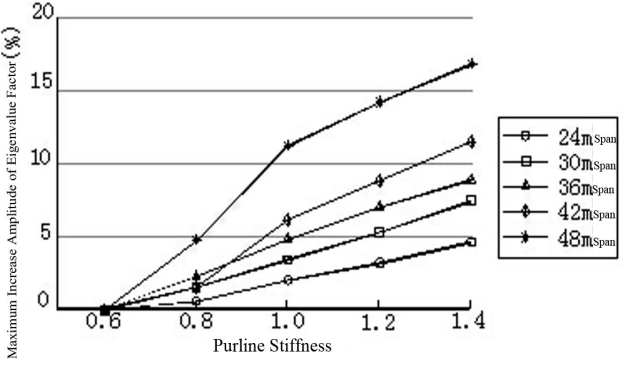

Figure 4 Changes of Eigenvalue Factor Increase amplitude with Purline Stiffness

From the aforesaid analysis results, it can be seen that with the increase of purline stiffness, the buckling eigenvalue factor continuously increases, and that means the buckling stable bearing capacity of portal frame will increase with the increase of purline stiffness. However, if spans are different, increase amplitudes are different. With the increase of span, the increase amplitude of buckling eigenvalue factor rises gradually, and that means purline stiffness has large influences on the stable bearing capacity of large-span portal frames.

\section{Ultimate bearing analysis of spatial stability}

Based on the buckling analysis, a nonlinear analysis is conducted by imposing initial geometric imperfections on portal frames to obtain an ultimate load. This paper adopts the consistent imperfection mode, and an eigenvalue buckling analysis is conducted on the structure model without initial geometric imperfections to obtain the buckling mode of the first order of overall buckling of rigid frame; the maximum displacement in ANSYS buckling mode deformation is normalized to 1 . According to Clause 8.2.8 of the Procedure, the lateral allowable deviation in cant beam installation is $\mathrm{L} / 1000$, and it is feasible to select an appropriate coefficient to change the deformation amplitude and the initial geometric imperfections of simulation structure. In consideration of influences of different purline stiffnesses, a nonlinear analysis is conducted on the portal frame of five different spans. The ultimate load factors of different models obtained from analysis results are shown in Table factors under different spans with purline stiffness.

Table 2 Eigenvalue Factor of Finite Element Model of Portal Frame

\begin{tabular}{c|c|c|c|c|c|c}
\hline \multirow{2}{*}{$\begin{array}{c}\text { Purline } \\
\text { stiffness }\end{array}$} & $\begin{array}{c}\text { Buckling } \\
\text { order }\end{array}$ & \multicolumn{5}{|c}{ Span } \\
\cline { 3 - 7 } & 1 & 3.45 & 3.22 & 3.14 & 2.61 & 2.32 \\
\hline \multirow{4}{*}{0.6} & 2 & 3.47 & 3.25 & 3.20 & 2.65 & 2.35 \\
\cline { 2 - 7 } & 3 & 3.49 & 3.28 & 3.26 & 2.69 & 2.38 \\
\hline \multirow{4}{*}{0.8} & 1 & 3.47 & 3.27 & 3.21 & 2.65 & 2.43 \\
\cline { 2 - 7 } & 2 & 3.50 & 3.31 & 3.23 & 2.71 & 2.48 \\
\cline { 2 - 7 } & 3 & 3.53 & 3.35 & 3.27 & 2.76 & 2.53 \\
\hline \multirow{4}{*}{1.0} & 1 & 3.52 & 3.33 & 3.29 & 2.77 & 2.58 \\
\cline { 2 - 7 } & 2 & 3.58 & 3.37 & 3.33 & 2.81 & 2.71 \\
\cline { 2 - 7 } & 3 & 3.63 & 3.41 & 3.37 & 2.86 & 2.76 \\
\hline \multirow{4}{*}{1.2} & 1 & 3.56 & 3.39 & 3.36 & 2.84 & 2.65 \\
\cline { 2 - 7 } & 2 & 3.60 & 3.42 & 3.39 & 2.88 & 2.80 \\
\cline { 2 - 7 } & 3 & 3.65 & 3.45 & 3.42 & 2.92 & 2.91 \\
\hline \multirow{4}{*}{1.4} & 1 & 3.61 & 3.46 & 3.42 & 2.91 & 2.71 \\
\cline { 2 - 7 } & 2 & 3.64 & 3.49 & 3.45 & 2.95 & 2.92 \\
\cline { 2 - 7 } & 3 & 3.67 & 3.52 & 3.49 & 2.99 & 3.02 \\
\hline
\end{tabular}

3; Figure 5 shows the changes of ultimate load

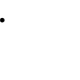




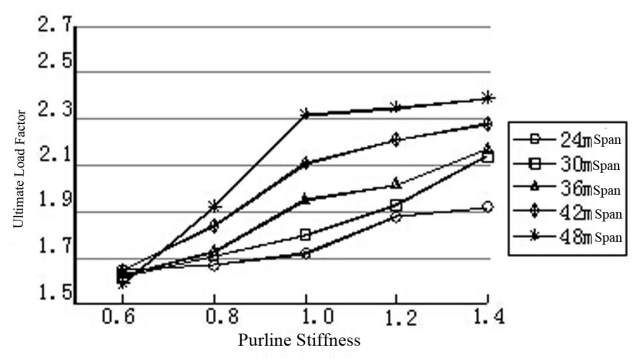

Fig. 5 Changes of Ultimate Load Factor under Different Spans with Purline Stiffness

\begin{tabular}{c|c|c|c|c|c}
\hline \multirow{2}{*}{$\begin{array}{c}\text { Purline } \\
\text { stiffness }\end{array}$} & \multicolumn{5}{|c}{ Span } \\
\cline { 2 - 6 } & $24 \mathrm{~m}$ & $30 \mathrm{~m}$ & $36 \mathrm{~m}$ & $42 \mathrm{~m}$ & $48 \mathrm{~m}$ \\
\hline 0.6 & 1.65 & 1.62 & 1.63 & 1.65 & 1.59 \\
\hline 0.8 & 1.67 & 1.71 & 1.73 & 1.84 & 1.92 \\
\hline 1.0 & 1.72 & 1.80 & 1.95 & 2.11 & 2.32 \\
\hline 1.2 & 1.88 & 1.93 & 2.02 & 2.21 & 2.35 \\
\hline 1.4 & 1.92 & 2.14 & 2.17 & 2.28 & 2.39 \\
\hline
\end{tabular}

From the aforesaid analysis results, it can be seen that with the increase of purline stiffness, the ultimate bearing capacity of portal frame continuously increases. The increase amplitudes of spans $24 \mathrm{~m}$ and $30 \mathrm{~m}$ are relatively small, and the increase amplitude of ultimate bearing capacity is not obvious when the purline stiffnesses are 0.6, 0.8 and 1.0; the increase amplitude of ultimate bearing capacity of portal frame with the spans of $36 \mathrm{~m}$ and $42 \mathrm{~m}$ is relatively large, but when the purline stiffnesses are 1.2 and 1.4, the increase amplitude of ultimate bearing capacity becomes small; as for the ultimate bearing capacity of portal frame with the span of $48 \mathrm{~m}$, when the purline stiffness is 1.0 and when the purline stiffness is 0.8 , the increase of ultimate bearing capacity is large; however, when the stiffness is 1.2 and 1.4 , respectively, the increase amplitude of ultimate bearing capacity is relatively small. That means purline stiffness has a large influence on large-span portal frames, and the increase of purline stiffness within a certain range can obviously improve the ultimate bearing capacity of portal frame.

\section{Conclusions}

Through the ANSYS finite element software, the paper analyzes the influence of different purline stiffnesses on the stability performance of portal frames of five different spans, obtaining the following analysis results:

1. The change of purline stiffness also has a certain influence on the buckling mode of large-span portal frames. When the purline stiffness is small, the anti-torsion and stability of purlines will be weak, causing them to be damaged relatively early.

2. With the increase of purline stiffness, the stable bearing capacity of portal frame continuously improves, but the improvement degree is different, and the influence on large-span portal frames is large. For the portal frame with the spans of $36 \mathrm{~m}$ and $42 \mathrm{~m}$, the increase amplitude of stable bearing capacity is relatively high, and when the purline stiffness is 1.0 , the stable bearing capacity will obviously improve; for the portal frame with the span of $48 \mathrm{~m}$, the stable bearing capacity will greatly improve, but when the purline stiffness are 1.2 and 1.4, the increase amplitude is relatively small.

\section{Acknowledgements}

This work was financially supported by the Science and Technology Project Plan of Housing and Urban-Rural Development Department of Shandong Province (1st batch), KY008, Research of Design Method of Portal Frame Structure Based on Spatial Overall Ultimate Bearing.

\section{References}

[1] Zhang Yannian, Wang Yuanqing, Shi Yongjiu. Reason and Case Analysis of Wind and SnowDisasters of Large-Span Lightweight Steel Construction [J]. Journal of Shenyang Jianzhu University,2011, 2(27): 272-280.

[2] Chen Zhihua, Sun Guojun. Design Research of Steel Structures Overcoming Snow Load Disasters[C] National Steel Structure Academic Annual Conference Proceedings, 2009. 
[3] Wang Wenhu, Zhang Wenyuan, Zhang Yaochun. Research of In-plane Stability of Portal Frameswith Different Depth-Span Ratios [J]. Low Temperature Architecture Technology, 2005, 5(103): 60-63.

[4] Zhang Jiuhai, Zhang Wenyuan. Analysis of In-Plane Elastic Overall Stability of Single-Layer and Solid-Web Portal Frames with Small Depth-Span Ratios [J], Housing Materials \& Applications, 2005,4(33): 4-7.

[5] Zhang Yaochun, Zhang Wenyuan, Zhang Jiuhai. Experimental Research of In-Plane Overall Stability of Solid-Web Portal Frames with Small Depth-Span Ratios [J]. China Civil Engineering Journal, 2005, 3 (38):38-41.

[6] GB 50017-2003 Code for Design of Steel Structures [S]. Beijing: China Planning Press, 2003

[7] GB 50018-2002 Technical Code of Cold-Formed Thin-Wall Steel Structures [S].Beijing: China Architecture \& Building Press, 2002

[8] CECS 102:2002 Technical Specification for Steel Structure of Light-Weight Buildings with Gabled Frames [S]. Beijing: China Planning Press, 2003 